RESEARCH REPORT

\title{
Mortality inequalities in times of economic growth: time trends in socioeconomic and regional inequalities in under 5 mortality in Indonesia, 1982-1997
}

\author{
Tanja A J Houweling, Anton E Kunst, Gerard Borsboom, Johan P Mackenbach
}

J Epidemiol Community Health 2006;60:62-68. doi: 10.1136/jech.2005.036079

\begin{abstract}
See end of article for authors' affiliations

Correspondence to:

T A J Houweling,

Department of Public

Health, Erasmus MC

University Medical Centre

Rotterdam, PO Box 1738,

3000 DR Rotterdam,

Netherlands; $a$.

houweling@erasmusmc.nl

Accepted for publication

1 August 2005
\end{abstract}

\begin{abstract}
Study objective: To examine time trends in socioeconomic and regional inequalities in under 5 mortality in Indonesia during almost two decades of economic growth.

Design: Under 5 mortality was calculated for the total population and for subgroups by maternal education, household wealth, rural/urban residence, and island group, using the 1987, 1991, 1994, and 1997 Indonesian Demographic and Health Surveys. Inequalities were calculated using Cox proportional hazards analysis.

Setting: Indonesia, 1982-1997.

Main participants: 18 205, 33 907, 39 433, and 37533 children respectively, aged under 5 years, born to women included in the above mentioned surveys.

Main results: Under 5 mortality declined substantially during the 1980s and 1990s. Educational inequalities in under 5 mortality decreased, although not statistically significantly, from a hazard ratio of $2.00(95 \% \mathrm{Cl} 1.60,2.50)$ to $1.52(95 \% \mathrm{Cl} 1.27,1.82)$. Inequalities between urban and not electrified rural areas increased, from $1.84(95 \% \mathrm{Cl} 1.48,2.28)$ to $2.18(95 \% \mathrm{Cl} 1.70,2.80)$. Inequalities between the Outer Islands and the central islands of Java/Bali increased from $1.16(95 \% \mathrm{Cl} 0.92,1.46)$ to $1.43(95 \% \mathrm{Cl}$ $1.17,1.74)$. Irregular time trends were seen for inequalities by household wealth. Trends in health care use were fairly similar for the low and high educated.

Conclusions: These results for education show that socioeconomic inequalities in under 5 mortality do not inevitably rise in times of rapid economic growth. Widening or narrowing of health inequalities in times of economic growth might depend on how equally this growth is distributed.
\end{abstract}

$\mathrm{R}$ educing socioeconomic and regional disparities in mortality within countries is an important objective of national governments and international organisations. ${ }^{1-4}$ Imperative to achieving this goal is identifying the conditions under which mortality inequalities decrease. Not much is known, however, about how inequalities change over time, and what the determinants of these changes are.

There are some indications that relative socioeconomic inequalities in mortality tend to increase in periods of economic growth and overall gains in survival. The existing evidence pertains to both high income countries, where such mortality inequalities have tended to rise during the past centuries, ${ }^{56}$ and, more recently, during the past decades, ${ }^{7-9}$ and to some developing countries. ${ }^{10-13}$ Empirical evidence, however, remains scarce, and is mostly restricted to a limited set of socioeconomic or regional determinants. ${ }^{14}$

Further evidence can be provided by the analysis of time trends in inequalities in countries experiencing rapid economic growth. The newly industrialising countries of Asia, which experienced sustained high economic growth since the 1970s until mid-1997, provide a valuable "laboratory" for such research. The availability of demographic and health survey data for Indonesia for four subsequent periods provides a unique opportunity to study such time trends during almost two decades of economic growth. The particularly large sample sizes make the Indonesian demographic and health surveys suitable for such an analysis.

Indonesia, the most populous country in South East Asia, was one of Asia's miracle economies. ${ }^{15}$ Its high economic growth was shared reasonably equally across wealth groups, with the ratio of household expenditures between the poor and the rich having remained similar since the 1970 s. $^{16}$
Poverty rates declined substantially, and nutritional standards improved. ${ }^{15}{ }^{16}$ Government investments in education were accompanied by strong increases in female literacy. The number of health care facilities expanded. ${ }^{15}{ }^{17}$ These changes were paralleled by strong declines in under 5 mortality. It is unknown to what extent this mortality decline has been equally shared across different groups within the country.

Our study aimed to describe trends in inequality in under 5 mortality in Indonesia between 1982 and 1997. Under 5 mortality is an often used indicator of population health. Moreover, in developing countries, data on under 5 mortality are comparatively reliable compared with other measures of population health. We studied inequalities in under 5 mortality along the following dimensions: maternal education, household wealth, rural-urban residence, and island group.

The set up of this study was guided by the conceptual framework described by Mosley and Chen, ${ }^{18}$ in which distal determinants such as maternal education exert an effect on under 5 mortality via more proximate determinants such as health care use. The effects of distal determinants like maternal education may also be explained by their association with other distal determinants, such as household wealth.

\section{METHODS}

Retrospective birth history data and data on determinants of under 5 mortality were obtained from the 1987, 1991, 1994, and 1997 Indonesian Demographic and Health Surveys. ${ }^{19}$ The Demographic and Health Surveys are nationally representative surveys among ever-married women aged 15-49 years. The sample sizes of the four Indonesian surveys are large: 
11884,22 909, 28 168, and 28810 women respectively. Response rates were high: $97 \%$ and above.

We defined under 5 mortality as the number of deaths under age 60 months per 5000 person years during the six years preceding the survey. Using person years instead of births as denominator assured that exactly the same information was used as in the analyses on mortality inequalities, as explained below. We used 5000 person years to obtain rates that have a roughly similar interpretation to the probability of dying within five years after birth. Children could enter the time frame at birth (in case they were born during the time frame) or at any age until 59 months (in case they were born before the start of the time frame). Data on age at death were available in months for deaths at age 2 years and below, and in years for deaths above that age. In the analyses, age at death in months was used where available. A six year time frame was used to ensure reasonable statistical power while limiting the recall bias involved with long time frames. Adjacent time frames partly overlap, which might lead to conservative estimates of changes over time.

Under 5 mortality was calculated for the total population and for educational, wealth, community, and island subgroups. Maternal education was categorised into four groups: "no education", "some primary education", "primary completed", and "some secondary schooling and higher". Household wealth was measured using an index based on ownership of assets, consisting of durable consumer goods, water and sanitation facilities, and housing quality. The assets were combined into a wealth index using weights derived through principal components analysis. ${ }^{20}{ }^{21}$ Despite its limitations, ${ }^{22}$ this index has gained fairly wide acceptance as a measure of economic status in developing countries. ${ }^{21} 23$ The principal components analysis was performed on a pooled dataset containing all survey years, with households as units of analysis. Consequently, the weighting scheme for the assets was the same for all years. Households were categorised into wealth groups, each consisting of $25 \%$ of the total household population in the pooled dataset. By using the same cut off points for all years to construct wealth groups, changes over time in wealth could be taken into account.

We distinguished three community types: urban, electrified rural, and not electrified rural. Rural-urban residence and the availability of electricity are known to influence child survival. ${ }^{24}$ Electricity was measured at the household level. As electricity is often communally provided, it is associated with community level availability and quality of infrastructure and services. Nevertheless, it may measure some household level effects in addition to community level effects.

Finally, we distinguished between the islands of Java and Bali-the political and economic centre of Indonesia-and the more peripheral Outer Islands, consisting of all other islands.

Inequalities in under 5 mortality by educational attainment, household wealth, rural/urban residence, and island group were estimated using Cox proportional hazards regression analysis. Inequalities were expressed in terms of hazard ratios, giving the ratio of the hazard of dying before age 60 months when comparing deprived with better off subgroups. For each of the determinants, inequalities in under 5 mortality were calculated for four periods separately using one regression model including an interaction term between predictor and survey year (survey year defined as ordinal variable). Overall time trends in inequality were tested by including survey year as continuous variable (instead of as ordinal variable) in the regression model. The trend estimates give the factor with which the hazard ratio changes between the 1987 and 1997 survey when modelling a linear time trend in effect.

Next, we assessed to what extent the observed inequalities could be explained by the other socioeconomic and regional determinants studied. For this purpose we added maternal education, household wealth, rural/urban residence, and island group to all the initial models. Both their main effects and their interaction effects with survey year were included, to allow for changes in their effect over time.

The demographic and health surveys are based on a cluster sampling scheme. Observations within clusters are likely to be more similar than those obtained through a simple random sample. To obtain correct confidence intervals around the hazard ratios and trend estimates, this design effect needs to be taken into account. Standard errors were obtained by bootstrapping the Cox analyses, keeping the number of clusters per survey year constant. For every model, 500 bootstrap replications were obtained. ${ }^{25}$

For each mother, on average, 1.5 children were included in the study. This intra-household dependency had no

Table 1 Distribution of children and number of deaths under age 60 months, by subgroup, Indonesia, Demographic and Health Surveys 1987, 1991, 1994, 1997

\begin{tabular}{|c|c|c|c|c|}
\hline \multirow[b]{2}{*}{ Subgroups } & \multicolumn{4}{|c|}{$\%$ Of children in category (number of deaths) } \\
\hline & $1982-1987$ & $1986-1991$ & 1989-1994 & 1992-1997 \\
\hline \multicolumn{5}{|l|}{ Maternal education } \\
\hline No education & $20(261)$ & $17(317)$ & $15(317)$ & $12(166)$ \\
\hline Some primary & $44(500)$ & 38 (779) & $34(613)$ & 28 (371) \\
\hline Primary completed & 20 (165) & 26 (424) & $28(452)$ & $31(416)$ \\
\hline Some secondary plus & $16(70)$ & $19(157)$ & $24(275)$ & $29(212)$ \\
\hline \multicolumn{5}{|l|}{ Household wealth } \\
\hline Poor & $28(394)$ & $30(646)$ & $29(670)$ & 20 (347) \\
\hline Next-poor & $28(286)$ & $27(469)$ & $24(442)$ & $23(280)$ \\
\hline Next-rich & $25(224)$ & $25(428)$ & $25(387)$ & $29(365)$ \\
\hline Rich & $19(92)$ & $18(129)$ & $21(152)$ & 28 (173) \\
\hline \multicolumn{5}{|l|}{ Community type } \\
\hline Not-electrified rural & $49(580)$ & 49 (987) & 39 (839) & $22(390)$ \\
\hline Electrified rural & $24(241)$ & 22 (329) & $33(550)$ & $52(554)$ \\
\hline Urban & $27(176)$ & $29(361)$ & $28(268)$ & $26(219)$ \\
\hline \multicolumn{5}{|l|}{ Island group } \\
\hline Outer Java/Bali & $40(435)$ & $44(744)$ & $43(793)$ & $44(606)$ \\
\hline Java/Bali & $60(562)$ & 56 (933) & $57(864)$ & $56(559)$ \\
\hline Total $^{*}$ & 18205 (997) & 33907 (1677) & $39433(1657)$ & $37533(1165)$ \\
\hline
\end{tabular}


Table 2 Trends in inequality in under 5 mortality by socioeconomic and regional groups, Indonesia, 1982-1997

\begin{tabular}{|c|c|c|c|c|c|c|}
\hline \multirow[b]{2}{*}{ Subgroup } & \multicolumn{6}{|c|}{ Under 5 mortality rates (number of deaths $/ 5000$ person years) } \\
\hline & $1982-87$ & $1986-91$ & 1989-94 & $1992-97$ & $\begin{array}{l}\% \text { Decline } \\
\text { between first } \\
\text { and last period }\end{array}$ & Trend estimate $(95 \% \mathrm{Cl})^{*}$ \\
\hline Total & 105.7 & 101.7 & 85.6 & 60.6 & 43 & \\
\hline \multicolumn{7}{|l|}{ Maternal education } \\
\hline No education & 137.9 & 110.3 & 113.1 & 74.9 & 46 & \\
\hline Some primary & 121.3 & 123.3 & 92.8 & 68.3 & 44 & \\
\hline Primary completed & 88.8 & 100.5 & 84.2 & 69.8 & 21 & \\
\hline Some secondary plus & 45.4 & 51.0 & 60.0 & 37.7 & 17 & \\
\hline Rate difference & 92.5 & 59.3 & 53.1 & 37.2 & & \\
\hline Hazard ratio† & $2.00(1.60,2.50)$ & $1.69(1.45,1.97)$ & $1.58(1.33,1.89)$ & $1.52(1.27,1.82)$ & & $0.88(0.68,1.13)$ \\
\hline \multicolumn{7}{|c|}{ 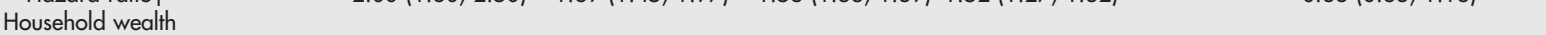 } \\
\hline Poor & 151.3 & 135.0 & 119.9 & 93.1 & 38 & \\
\hline Next-poor & 109.3 & 103.5 & 96.1 & 61.9 & 43 & \\
\hline Next-rich & 94.7 & 103.8 & 79.0 & 64.8 & 32 & \\
\hline Rich & 50.1 & 43.8 & 36.7 & 32.4 & 35 & \\
\hline Rate difference & 101.2 & 91.2 & 83.3 & 60.7 & & \\
\hline Hazard ratio† & $1.70(1.38,2.08)$ & $1.48(1.26,1.74)$ & $1.78(1.47,2.16)$ & $1.57(1.27,1.95)$ & & $1.04(0.81,1.33)$ \\
\hline \multicolumn{7}{|c|}{ (2) } \\
\hline Not electrified rural & 126.9 & 124.0 & 112.4 & 92.7 & 27 & \\
\hline Electrified rural & 108.2 & 89.1 & 84.3 & 55.1 & 49 & \\
\hline Urban & 66.9 & 74.7 & 49.9 & 44.0 & 34 & \\
\hline Rate difference & 60.1 & 49.3 & 62.5 & 48.8 & & \\
\hline Hazard ratio & $1.84(1.48,2.28)$ & $1.61(1.25,2.06)$ & $2.24(1.66,3.01)$ & $2.18(1.70,2.80)$ & & $1.36(0.99,1.86)$ \\
\hline \multicolumn{7}{|l|}{ Island group } \\
\hline Outer Islands & 117.9 & 102.8 & 94.4 & 72.9 & 38 & \\
\hline Java/Bali & 97.9 & 100.8 & 78.8 & 51.2 & 48 & \\
\hline Rate difference & 20.0 & 2.0 & 15.6 & 21.7 & & \\
\hline Hazard ratio§ & $1.16(0.92,1.46)$ & $1.01(0.84,1.22)$ & $1.21(1.02,1.45)$ & $1.43(1.17,1.74)$ & & $1.27(0.96,1.67)$ \\
\hline
\end{tabular}

noticeable effect on the standard errors. Cox analyses and bootstraps were done in s-PLus 6.0.

Inequalities were also calculated for infant mortality (mortality under age 12 months) and child mortality (mortality between age 12 and 59 months) separately, as the strength of the effects of the studied determinants is known to vary with the age of children.

Finally, a first step towards explaining time trends in inequality was set by calculating time trends in health care use for educational and island subgroups.

Table 3 Multivariate analyses: trends in inequality in under 5 mortality by socioeconomic and regional groups, Indonesia, 1982-1997

\begin{tabular}{|c|c|c|c|c|c|c|c|c|c|c|c|c|}
\hline & \multicolumn{12}{|c|}{ Hazard ratios $(95 \% \mathrm{Cl}):$ univariate and after adjustment } \\
\hline & \multicolumn{3}{|c|}{$1982-87$} & \multicolumn{3}{|c|}{$1986-91$} & \multicolumn{3}{|c|}{ 1989-94 } & \multicolumn{3}{|c|}{$1992-97$} \\
\hline & $\overline{\mathrm{HR}}$ & $95 \%$ & $\mathrm{Cl}$ & $\overline{\mathrm{HR}}$ & $95 \%$ & $\mathrm{Cl}$ & $\overline{H R}$ & $95 \%$ & $\mathrm{Cl}$ & $\overline{\mathrm{HR}}$ & $95 \%$ & $\mathrm{Cl}$ \\
\hline Maternal education & 2.00 & 1.60 & 2.50 & 1.69 & 1.45 & 1.97 & 1.58 & 1.33 & 1.89 & 1.52 & 1.27 & 1.82 \\
\hline \multicolumn{13}{|l|}{ Adjusted for: } \\
\hline Household wealth & 1.62 & 1.29 & 2.04 & 1.44 & 1.23 & 1.69 & 1.27 & 1.05 & 1.53 & 1.26 & 1.04 & 1.52 \\
\hline Community type & 1.80 & 1.43 & 2.25 & 1.56 & 1.32 & 1.84 & 1.38 & 1.15 & 1.64 & 1.32 & 1.10 & 1.59 \\
\hline Island group & 1.97 & 1.56 & 2.49 & 1.68 & 1.44 & 1.96 & 1.58 & 1.33 & 1.88 & 1.52 & 1.28 & 1.81 \\
\hline All & 1.62 & 1.28 & 2.04 & 1.42 & 1.21 & 1.67 & 1.26 & 1.05 & 1.51 & 1.25 & 1.03 & 1.51 \\
\hline Household wealth & 1.70 & 1.38 & 2.08 & 1.48 & 1.26 & 1.74 & 1.78 & 1.47 & 2.16 & 1.57 & 1.27 & 1.95 \\
\hline Maternal education & 1.32 & 1.08 & 1.62 & 1.18 & 0.99 & 1.41 & 1.52 & 1.21 & 1.91 & 1.29 & 1.04 & 1.60 \\
\hline Community type & 1.46 & 1.13 & 1.90 & 1.27 & 1.01 & 1.59 & 1.41 & 1.15 & 1.72 & 1.23 & 0.96 & 1.57 \\
\hline Island group & 1.69 & 1.40 & 2.04 & 1.49 & 1.24 & 1.80 & 1.77 & 1.46 & 2.14 & 1.51 & 1.22 & 1.88 \\
\hline All & 1.24 & 0.97 & 1.58 & 1.09 & 0.88 & 1.35 & 1.27 & 1.03 & 1.55 & 1.06 & 0.84 & 1.36 \\
\hline Community type* & 1.84 & 1.48 & 2.28 & 1.61 & 1.25 & 2.06 & 2.24 & 1.66 & 3.01 & 2.18 & 1.70 & 2.80 \\
\hline \multicolumn{13}{|l|}{ Adjusted for: } \\
\hline Maternal education & 1.42 & 1.13 & 1.79 & 1.26 & 0.96 & 1.64 & 1.84 & 1.38 & 2.46 & 1.70 & 1.32 & 2.20 \\
\hline Household wealth & 1.23 & 0.93 & 1.62 & 1.14 & 0.83 & 1.57 & 1.43 & 1.05 & 1.94 & 1.44 & 1.06 & 1.95 \\
\hline Island group & 1.81 & 1.46 & 2.25 & 1.63 & 1.26 & 2.11 & 2.20 & 1.66 & 2.92 & 2.02 & 1.57 & 2.60 \\
\hline All & 1.15 & 0.84 & 1.57 & 1.06 & 0.77 & 1.46 & 1.38 & 0.98 & 1.93 & 1.19 & 0.86 & 1.63 \\
\hline Island group & 1.16 & 0.92 & 1.46 & 1.01 & 0.84 & 1.22 & 1.21 & 1.02 & 1.45 & 1.43 & 1.17 & 1.74 \\
\hline \multicolumn{13}{|l|}{ Adjusted for: } \\
\hline Maternal education & 1.12 & 0.90 & 1.39 & 1.02 & 0.85 & 1.23 & 1.24 & 1.05 & 1.47 & 1.55 & 1.26 & 1.90 \\
\hline Household wealth & 1.13 & 0.90 & 1.42 & 0.95 & 0.79 & 1.15 & 1.12 & 0.93 & 1.34 & 1.30 & 1.05 & 1.59 \\
\hline Community type & 1.10 & 0.86 & 1.40 & 0.95 & 0.78 & 1.15 & 1.07 & 0.89 & 1.29 & 1.24 & 1.01 & 1.53 \\
\hline All & 1.10 & 0.89 & 1.37 & 0.99 & 0.82 & 1.19 & 1.11 & 0.93 & 1.33 & 1.35 & 1.10 & 1.67 \\
\hline
\end{tabular}




\section{RESULTS}

During the 1980s and 1990s, the Indonesian population has become better educated and wealthier. This is reflected in an increase in the proportion of children born to mothers with at least some secondary education and a decrease in the proportion of children born in poor or next-poor households (table 1). The proportion of children born in not-electrified rural areas decreased by more than $50 \%$.

Table 2 shows time trends in under 5 mortality. Total under 5 mortality declined by $43 \%$ between the 1987 and 1997 survey. All socioeconomic and regional groups experienced improvements in survival. Small deviations from the monotonic mortality decline are possibly attributable to chance. The more substantial mortality increases between the first and second survey among children of higher educated, nextrich, and urban women seemed to be concentrated in the province of West Java (results not shown). The causes of this mortality increase remain unknown.

Children born to low educated mothers experienced stronger mortality declines than children of high educated mothers. Hence, the educational mortality gap decreased systematically. In 1982-87, children of low educated mothers were twice as likely to die before their 5 th birthday compared with children of high educated mothers. This mortality gap decreased to a ratio of 1.52 in 1992-1997. The decrease was not statistically significant, as indicated by the $95 \% \mathrm{CI}$ around the trend estimate. When comparing the two extreme educational groups, "no education" and "some secondary plus", a not statistically significant decline in inequality was seen, from a ratio of $3.42(95 \%$ CI $2.41,4.85)$ in $1982-87$ to $2.54(95 \%$ CI $1.87,3.46)$ in 1992-97. Mortality differences between the lowest three educational groups virtually disappeared in 1992-97.

An irregular pattern of change over time was seen for mortality inequalities according to household wealth. Nevertheless, absolute poor-rich inequalities decreased, because of stronger absolute mortality declines among poorer groups.

The relative mortality gap between urban and notelectrified rural areas widened. This increase was borderline

Table 4 Trends in health care use by educational and island groups, Indonesia, 19871997

\begin{tabular}{ll}
$\frac{\%}{\%}$ Of population & \\
\hline Educational attainment & Island group \\
\hline Low educated High educated & $\begin{array}{l}\text { Outer } \\
\text { Java/Bali Java/Bali }\end{array}$
\end{tabular}

\begin{tabular}{|c|c|c|c|c|}
\hline \multicolumn{5}{|l|}{ Measles vaccination coverage* } \\
\hline DHS 1991 & 47 & 67 & 47 & 66 \\
\hline DHS 1994 & 46 & 74 & 58 & 66 \\
\hline DHS 1997 & 56 & 78 & 70 & 72 \\
\hline absolute change between 1991-97† & 9 & 11 & 23 & 6 \\
\hline \multicolumn{5}{|l|}{ Antenatal care } \\
\hline \multicolumn{5}{|l|}{ DHS 1987} \\
\hline DHS 1991 & 70 & 90 & 75 & 84 \\
\hline DHS 1994 & 78 & 94 & 84 & 90 \\
\hline DHS 1997 & 85 & 97 & 91 & 94 \\
\hline absolute change between 1991-97† & 15 & 6 & 16 & 10 \\
\hline \multicolumn{5}{|l|}{ Skilled delivery attendance§ } \\
\hline DHS 1987 & 24 & 57 & 45 & 31 \\
\hline DHS 1991 & 20 & 51 & 38 & 33 \\
\hline DHS 1994 & 21 & 54 & 44 & 37 \\
\hline DHS 1997 & 26 & 61 & 52 & 47 \\
\hline absolute change between 1991-97† & 6 & 10 & 14 & 14 \\
\hline \multicolumn{5}{|l|}{ Births with tetanus vaccination } \\
\hline \multicolumn{5}{|l|}{ DHS 1987} \\
\hline DHS 1991 & 46 & 71 & 48 & 67 \\
\hline DHS 1994 & 53 & 76 & 57 & 73 \\
\hline DHS 1997 & 60 & 80 & 68 & 77 \\
\hline absolute change between 1991-97† & 14 & 9 & 21 & 10 \\
\hline \multicolumn{5}{|l|}{ Current use of modern family planning ${ }^{* *}$} \\
\hline DHS 1987 & 35 & 49 & 33 & 44 \\
\hline DHS 1991 & 38 & 50 & 37 & 47 \\
\hline DHS 1994 & 42 & 54 & 42 & 52 \\
\hline DHS 1997 & 45 & 55 & 45 & 55 \\
\hline absolute change between 1991-97† & 8 & 5 & 8 & 8 \\
\hline \multicolumn{5}{|l|}{ Knowledge of ORSt† } \\
\hline \multicolumn{5}{|l|}{ DHS 1987} \\
\hline DHS 1991 & 76 & 95 & 81 & 89 \\
\hline DHS 1994 & 78 & 96 & 87 & 88 \\
\hline DHS 1997 & 83 & 96 & 90 & 92 \\
\hline absolute change between 1991-97† & 7 & 1 & 9 & 3 \\
\hline
\end{tabular}

Low educated: no education or some primary, high educated: primary completed or higher. DHS: Demographic and Health Surveys. In DHS 1987, data were not available for a number of indicators. *Measles: \% of surviving children age 12-23 months (at time of survey) with measles vaccination, by vaccination card or mother's report. †Measures the absolute change in rate between DHS 1991 and 1997. ¥Antenatal care: \% of births in the five years before the survey for which a woman received at least one antenatal care consultation from a medically trained person, defined as a doctor, nurse, or nurse midwife. §Skilled delivery attendance: $\%$ of births in the five years before the survey that were attended to by a medically trained person, defined as a doctor, nurse, or nurse midwife. Births with tetanus vaccination: \% pregnancies during which tetanus toxoid injections were given to avoid convulsions after birth. ${ }^{*}$ Current use of modern family planning methods: \% of married women aged 15-49 years. †† Knowledge of ORS: \% mothers having heard of ORS (oral rehydration) for treating children with diarrhoea. 
significant. In 1992-97, under 5 mortality in not-electrified rural areas was 2.18-fold higher than in urban areas (95\%CI $1.70,2.80)$. Mortality inequalities between not-electrified and electrified rural areas increased statistically significantly (results available on request).

Mortality differences between Java/Bali and the Outer Islands were small or non-existent during the 1980s. These inequalities, however, emerged and increased during the 1990s, because of stronger mortality declines on Java/Bali. In 1992-97, under 5 mortality on the Outer Islands was 1.44fold higher than on Java/Bali (95\%CI 1.17, 1.74). This increase was borderline significant.

Table 3 shows the extent to which the observed inequalities were explained by other factors. Educational mortality inequalities were partly (50\% in 1992-97) explained by household wealth. However, the observed decline over time in educational mortality inequalities was not explained by household wealth (this decline was also seen after adding wealth to the regression model). This was checked and confirmed by using three alternative wealth measures, such as a regression model including all wealth indicators separately as dummies (see appendix available on line). Nor was the observed decline in inequalities explained by rural/urban residence or island group.

Mortality differences between poor and rich children were for about 50\% explained by maternal education. In 1992-97, for example, the hazard ratio after adjustment for education (1.29) was about halfway between 1 (indicating no effect) and 1.57 (the univariate effect of wealth). Household wealth lost most of its statistically significant association with under 5 mortality after adjusting for education, rural/urban residence and island group, with $95 \%$ CIs including 1 in three of the four periods.

Differences in under 5 mortality between urban and notelectrified rural communities were largely explained by household wealth, maternal education, and to a lesser extent by island group. Only in 1989-94, substantial inequalities remained after adjusting for the above mentioned factors.

The widening mortality gap between Java/Bali and the Outer Islands was partly explained by household wealth, and more strongly by rural/urban residence. Adjustment for education showed that the greater improvements in educational attainment on the Outer Islands dampened the trend of widening regional mortality inequalities. In 1992-97, a moderately large and statistically significant mortality gap remained between the island groups after adjusting for all factors.

Socioeconomic and regional inequalities in child (1259 months) mortality were overall substantially larger than those in infant (0-11 months) mortality, especially in later periods (see appendix available on line). Educational inequalities seem to decline for both infant and child mortality. Neither trends were, however, statistically significant. Inequalities in child mortality by household wealth and between urban and not-electrified rural areas increased strongly and significantly. Time trends in inequality in infant mortality by these factors were weaker and not significant. The gap between island groups in infant and child mortality increased over time, although the changes were not statistically significant.

Health care use has, overall, increased (table 4). Low educated mothers probably experienced somewhat stronger increases in antenatal care, tetanus vaccination, family planning, and knowledge of oral rehydration solution. Conversely, higher educated mothers probably experienced a somewhat stronger increase in skilled delivery attendance. Educational inequalities in skilled delivery attendance, and measles and tetanus vaccination remained large.

\section{What this paper adds}

- Time trends in mortality inequalities have rarely been described in such detail for a low income country.

- We are the first to show for Indonesia that children of low educated mothers experienced at least as strong mortality declines as children of high educated mothers. Hence, the gap in under 5 mortality between the low and high educated possibly narrowed.

- However, peripheral areas seem to lag behind the progress in under 5 survival experienced by urban areas and the central islands of Java and Bali.

On the Outer Islands, health care use (especially measles vaccination, antenatal care, and tetanus vaccination) improved considerably over time. Whereas in 1991 utilisation rates were substantially lower on the Outer Islands than on Java/Bali, this difference was generally smaller or had disappeared in 1997.

\section{DISCUSSION}

Under 5 mortality declined substantially in Indonesia during the 1980s and 1990s. This decline seems to be unequally distributed across socioeconomic groups and across regions. The mortality declines were possibly stronger among children of low educated mothers than children of high educated mothers. Hence, the mortality gap between the low and high educated possibly narrowed. Peripheral areas lag behind the mortality progress experienced by urban areas and the central islands of Java and Bali. Irregular time trends were seen for relative inequalities according to household wealth. Absolute mortality inequalities generally decreased over time.

Educational inequalities in under 5 mortality nevertheless remained substantial during the last study period. Under 5 mortality was 2.5 -fold higher among children of uneducated mothers than among children of mothers with some secondary education. Also regional inequalities were large. Indonesia, with a population of over 200 million, would achieve tremendous gains in under 5 survival if disadvantaged groups and regions would reach the same mortality levels as the better off.

Differences in under 5 mortality between children of women with/without primary education virtually disappeared over time, suggesting that, under conditions prevailing in 1997, only improvements in female education beyond primary school level would substantially improve under 5 survival.

\section{Evaluating the data and methods}

When evaluating the observed decline in educational mortality inequalities, two issues should be considered.

\section{Policy implications}

- The stable or declining inequalities in under 5 mortality by maternal education challenge the assumption that socioeconomic mortality inequalities tend to rise during a period of rapid economic growth.

- Our paper suggests that an equitable distribution of the benefits of economic growth in general and rural development in particular may be important factors for preventing widening inequalities in under 5 mortality. 
Firstly, there was not enough statistical power to exclude the possibility that this decline was attributable to chance variations. The limited statistical power is related to the necessary adjustment for cluster sampling in the Demographic and Health Surveys, an adjustment that many studies omit. Even with huge datasets like the Indonesian Demographic and Health Surveys, it remains difficult to precisely establish time trends in inequality. Nevertheless, the systematic nature of the decline in inequality over four periods, and the similar pattern observed for infant and child mortality, does suggest this decline was real. Important to note, there are no indications that educational mortality inequalities increased over time. Secondly, the observed decline in inequality cannot be explained by a stronger negative selection of the low educated over time. Negative selection means that as having a low educational attainment becomes more an exception (table 1), it is increasingly associated with characteristics that instigate high mortality. Such an increased selection would imply increasing, instead of decreasing inequalities.

The irregular time trends in inequality according to household wealth are possibly attributable to problems with comparability of the wealth measure over time. It is not likely that the effect of wealth fluctuates strongly within short periods of time, perhaps except in the case of severe economic or societal disruption. Whereas the wealth index has gained fairly wide acceptance as measure of economic status in developing countries, its usefulness in time trend analyses seems to be restricted. Future research should pay attention to improving the wealth index in this respect.

\section{Explaining the results}

Stable or declining educational inequalities in under 5 mortality are remarkable, as they contrast with indications that mortality inequalities generally increase in times of rapid economic growth. ${ }^{10-13}$ Especially educational inequalities can be expected to increase, as maternal education has been shown to be a crucial factor in adopting "modern" health behaviour and taking advantage of new health technologies. ${ }^{26}{ }^{27}$ We will discuss three explanations for the observed narrowing mortality gap. Thereafter, we will discuss explanations for the increasing regional inequalities.

Firstly, mortality inequalities might decline once the better off have reached a (contextually defined) saturation point beyond which further improvements are not attainable. ${ }^{11}$ This, however, cannot explain our results. Even if further mortality declines were difficult to attain among the highest educated, they were attainable among all other educational groups. Yet, also among these groups, a clear gradient was seen, with the lower educated experiencing stronger mortality declines.

Secondly, an increased availability of health care and family planning services may have contributed to faster declines in under 5 mortality among the low educated. ${ }^{28}{ }^{29} \mathrm{In}$ Indonesia, the network of community health centres that was set up throughout the country during the 1970s, ${ }^{15}$ was expanded with lower level sub-centres and village health posts during the 1980s. ${ }^{17}$ Although health facilities have increased in quantity, there are important concerns over quality and accessibility for the poor. ${ }^{17}$ We found no strong indication that increased health care use contributed to the observed narrowing mortality gap. The trends in health care use only differed slightly between educational groups, and the strongest increases were not consistently concentrated among the lower educated. Another study showed that the total fertility rate declined most strongly, from 3.7 births in 1984 to 2.7 in 1997, among uneducated women, whereas it remained stable at around 2.6 births among the high educated..$^{30}$ Lower fertility rates are, via longer birth intervals, associated with lower under 5 mortality rates. ${ }^{31}{ }^{32}$ This may have contributed to the observed decline in educational inequalities in under 5 mortality in general, and in infant mortality in particular.

Finally, an equal sharing of economic growth across socioeconomic groups may contribute to a faster mortality decline among the low educated. An equitable income distribution and the accompanying poverty decline have been lauded as one of the hallmarks of Indonesia's high economic growth. ${ }^{15} 16$ The poor-rich ratio of household expenditure had not fundamentally changed since the 1970s, showing that both groups benefited about equally from the economic boom. ${ }^{16}$ The poverty decline may have disproportionately benefited the low educated. Nevertheless, household wealth could not explain, in a multivariate analysis, the observed decline in educational mortality inequalities. Moreover, the availability of water and sanitation facilities did not change substantially (results available on request). More specific mechanisms, such as an improvement in the nutritional status of mothers and young children, may have been at work. It has been estimated that malnutrition is an underlying factor in 54\% of all child deaths in Indonesia.. ${ }^{33}$ Malnutrition has declined steadily during the economic growth period, thanks to the Green Revolution and the government's pro-active food policy. ${ }^{16}$ Moreover, socioeconomic differences in child malnutrition declined in Indonesia during the 1990s. ${ }^{34}$

The small mortality differences between Java/Bali and the Outer Islands during the 1980s might have been partly related to the mildly equalising fiscal flows between the centre and periphery during the mid-1970s until the early 1990s. ${ }^{16}$ In the early 1990s, economic growth became more concentrated on Java. ${ }^{15}$ In rural Java/Bali, the prevalence of household poverty decreased somewhat faster and the percentage of children living without electricity declined much faster than in rural areas of the Outer Islands (results available on request). Our multivariate analysis confirmed that the increasing mortality gap between Java/Bali and the Outer Islands might be partly explained by a faster rural development on Java/Bali.

Differential trends in health care use and fertility cannot explain the increasing mortality gap between the island groups. Improvements in health care use were much stronger on the Outer Islands than on Java/Bali. Others have shown that also declines in total fertility were stronger on the Outer Islands. ${ }^{30}$

Summarising, during the Asian economic boom, children of low educated mothers experienced at least as strong mortality declines as children of high educated mothers. Hence, the mortality gap between the low and high educated possibly narrowed. This was not a necessity, caused by "saturation" in the mortality decline among the higher educated. Rather, the Indonesian economic and political context has probably been conducive to this development. The reasonably equitable distribution of economic growth across socioeconomic groups in Indonesia ${ }^{15}{ }^{16}$ may have prevented rising educational inequalities in mortality. The specific mechanisms that contributed to the observed decline in inequality are, however, uncertain. Whereas improvements in household wealth seemed not to explain the observed trend, improved nutritional status among low educated mothers and their children might be an explanation. Unequal economic growth between the central islands of Java/Bali and the more peripheral Outer Islands, and especially a faster rural development on Java/Bali, may have contributed to the increasing regional mortality inequalities. This suggests that the diverging trends in mortality inequalities by education and island group might be explained by the same mechanism-that is, distribution of economic growth. 
This distribution was comparatively equitable across socioeconomic groups, thereby possibly preventing widening educational mortality inequalities. Conversely, a stronger concentration of economic growth on Java/Bali may have contributed to the increasing regional mortality gap.

Our results for Indonesia might be exemplary for a broader set of newly industrialising Asian countries. These countries have followed a similar development trajectory, with high economic growth, a rather equitable income distribution, and governments with "development agendas". ${ }^{15}$ Further research should discover if this shared development trajectory was accompanied by shared time trends in mortality inequalities.

The Asian economic boom was followed in mid-1997 by an economic crisis, which has severely affected economic wellbeing and possibly also health of the Indonesian population. The inequalities observed for 1992-97 may therefore not be fully applicable to the current situation. Mortality inequalities are, however, likely to have persisted, and may even have widened. The recent developments only further emphasise the importance of understanding how inequalities in mortality develop with a country's macroeconomic conditions.

\section{Implications}

Our study implies that widening socioeconomic mortality inequalities in times of rapid economic growth are not inevitable; declining inequalities may occur as well, certainly in absolute sense. What happens with mortality inequalities in times of economic growth might depend on how equally this growth is distributed. An equitable distribution of economic growth in general, and rural development in particular, might be important factors for preventing widening inequalities in under 5 mortality. Secondly, our results show that stable or declining inequalities according to one dimension can go together with increasing inequalities in another. This underlines the importance of monitoring mortality inequalities across a broad range of socioeconomic and regional dimensions. Further unravelling of historical trends in mortality inequalities is pivotal for a better understanding of the specific conditions that increase or impede an equal distribution of survival opportunities.

\section{ACKNOWLEDGEMENTS}

We thank the three reviewers for their comments and suggestions on an earlier draft of this paper and we thank Casper WN Looman for his statistical advice.

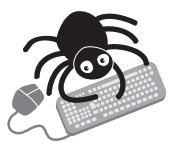

The appendix showing trends in inequality in infant and child mortality by socioeconomic and regional groups, Indonesia, 1982-1997 is available on line (http://www.jech.com/supplemental).

\section{Authors' affiliations}

T A J Houweling, A E Kunst, G Borsboom, J P Mackenbach, Department of Public Health, Erasmus MC University Medical Centre Rotterdam, Rotterdam, Netherlands

Funding: the Netherlands Medical Sciences Research Council (Zon/Mw) financed this study.

Conflicts of interest: none declared.

\section{REFERENCES}

1 WHO. The world health report 2000; health systems: improving performance. Geneva: World Health Organisation, 2000.
2 Evans T, Whitehead M, Diderichsen $\mathrm{F}$, et al, eds. Challenging inequities in health: from ethics to action. Oxford: Oxford University Press, 2001

3 Braveman P, Gruskin S. Poverty, equity, human rights and health. Bull World Health Organ 2003;81:539-45.

4 Victora CG, Wagstaff A, Schellenberg JA, et al. Applying an equity lens to child health and mortality: more of the same is not enough. Lancet 2003;362:233-41

5 Burstrom B, Macassa G, Oberg L, et al. Equitable child health interventions: the impact of improved water and sanitation on inequalities in child mortality in Stockholm, 1878 to 1925. Am J Public Health 2005;95:208-16.

6 Mheen Dvd. Inequalities in health, to be continued? A life-course perspective on socio-economic inequalities in health. (PhD thesis). Rotterdam: Erasmus University Rotterdam, 1998.

7 Martikainen P, Valkonen T, Martelin T. Change in male and female life expectancy by social class: decomposition by age and cause of death in Finland 1971-95. J Epidemiol Community Health 2001;55:494-9.

8 Marang-van de Mheen P, Davey Smith G, Hart C, et al. Socioeconomic differentials in mortality among men within Great Britain: time trends and contributory causes. J Epidemiol Community Health 1998;52:214-18.

9 Mackenbach JP, Bos V, Andersen O, et al. Widening socioeconomic inequalities in mortality in six Western European countries. Int J Epidemiol 2003;32:830-7.

10 Wagstaff A. Inequalities in health in developing countries: swimming against the tide? Washington, DC: World Bank, 2002.

11 Victora CG, Vaughan JP, Barros FC, et al. Explaining trends in inequities: evidence from Brazilian child health studies. Lancet 2000;356:1093-8.

12 DaVanzo J, Habicht J-P. Infant mortality decline in Malaysia, 1946-1975: he roles of changes in variables and changes in the structure of relationships. Demography 1986;23:143-60.

13 Vega J, Hollstein RD, Delgado I, et al. Chile: socioeconomic differentials and mortality in a middle-income nation. In: Evans T, Whitehead M, Diderichsen F, et al, eds. Challenging inequities in health: from ethics to action. Oxford: Oxford University Press, 2001.

14 Woods R, Williams N. Must the gap widen before it can be narrowed? Longterm trends in social class mortality differentials. Continuity and Change 1995; 10:105-37

15 BPS, BAPPENAS, UNDP. Indonesia human development report 2001: towards a new consensus. Democracy and human development in Indonesia. Jakarta: BPS, BAPPENAS, UNDP, 2001

16 Hill H. The Indonesian economy since 1966: Southeast Asia's emerging giant. Cambridge: Cambridge University Press, 1996.

17 Hull TH, Hull VJ. Population and health policies. In: Booth A, eds. The oil boom and after: Indonesian economic policy and performance in the Soeharto era. Oxford: Oxford University Press, 1995:411-36.

18 Mosley WH, Chen LC. An analytical framework for the study of child survival in developing countries: child survival: strategies for research. Population and Development Review 1984;10(suppl):25-45.

19 Indonesian demographic and health surveys. http://www.measuredhs.com.

20 Gwatkin DR, Rutstein S, Johnson K, et al. Socio-economic differences in health, nutrition, and population. Washington: The World Bank, 2000.

21 Filmer D, Pritchett LH. Estimating wealth effects without expenditure data-or tears: an application to educational enrollments in states of India. Demography 2001;38:115-32.

22 Houweling TA, Kunst AE, Mackenbach JP. Measuring health inequality among children in developing countries: does the choice of the indicator of economic status matter? Int J Equity Health 2003;2:8.

23 Bollen KA, Glanville JL, Stecklov G. Economic status proxies in studies of fertility in developing countries: Does the measure matter? Population StudiesA Journal of Demography 2002;56:81-96.

24 Wang L. Determinants of child mortality in LDCs: empirical findings from demographic and health surveys. Health Policy 2003;65:277-99.

25 Efron B, Tibshirani RJ. An introduction to the bootstrap. New York: Chapman and Hall, 1993.

26 Cleland JG, Ginneken JKv. Maternal education and child survival in developing countries: the search for pathways of influence. Soc Sci Med 1988;27:1357-68.

27 Caldwell JC. Cultural and social factors influencing mortality levels in developing countries. Ann Am Acad Pol Soc Sci 1990;510:44-59.

28 Bicego G. Trends, age-patterns, and determinants of childhood mortality in Haiti. (PhD thesis). Baltimore: The Johns Hopkins University, 1990.

29 Rozenzweig M, TP S. Child mortality and fertility in Colombia: individual and community effects. Health Policy Educ 1982;2:305-48.

30 Central Bureau of Statistics (CBS) (Indonesia), State Ministry of Population/ National Family Planning Coordinating Board Ministry of Health, Macro International (MI). Trends in demographic, family planning, and health indicators in Indonesia, 1971-1997. Calverton, MD: CBS and MI, 1998.

31 Setty-Venugopal V, Upadhyay UD. Birth spacing: three to five saves lives. Population reports. Baltimore: Johns Hopkins Bloomberg School of Public Health, Population Information Program, 2002.

32 Barnum H. Interaction of infant mortality and fertility and the effectiveness of health and family planning programs. Washington: Population and Human Resources Department, The World Bank, 1988.

33 Pelletier DL, Frongillo EAJ, Schroeder DG, et al. The effects of malnutrition on child mortality in developing countries. Bull World Health Organ 1995;73:443-8.

34 Waters H, Saadah F, Surbakti S, et al. Weight-for-age malnutrition in Indonesian children, 1992-1999. Int J Epidemiol 2004;33:589-95. 